\title{
A GDPase/UDPase Bifunctional Enzyme From Candida Albicans: Purification and Biochemical Characterization
}

Jaime Alberto Bibián-García

Universidad de Guanajuato

Jorge Armando Ortiz-Ramírez

Universidad de Guanajuato

Lilia Maritza Almanza-Villegas

Universidad de Guanajuato

Ma. del Carmen Cano-Canchola

Universidad de Guanajuato

Mayra Cuéllar-Cruz

Universidad de Guanajuato

Everardo López-Romero ( $\square$ everlope@ugto.mx )

Universidad de Guanajuato

\section{Research Article}

Keywords: C. albicans, Nucleotidases, GDPase/UDPase

Posted Date: December 10th, 2021

DOI: https://doi.org/10.21203/rs.3.rs-1143372/v1

License: (1) This work is licensed under a Creative Commons Attribution 4.0 International License.

Read Full License

Version of Record: A version of this preprint was published at Antonie van Leeuwenhoek on February

17th, 2022. See the published version at https://doi.org/10.1007/s10482-022-01714-y. 


\section{Abstract}

The most frequently isolated human fungal pathogen is Candida albicans which is responsible for about $50 \%$ of all Candida infections. In healthy individuals, this organism resides as a part of the normal microbiota in equilibrium with the host. However, under certain conditions, particularly in immunocompromised patients, this opportunistic pathogen adheres to host cells causing serious systemic infections. Thus, much effort has been dedicated to the study of its physiology with emphasis on factors associated to pathogenicity. A representative analysis deals with the mechanisms of glycoprotein assembly as many cell surface antigens and other macromolecules that modulate the immune system fall within this chemical category. In this regard, studies of the terminal protein glycosylation stage which occurs in Golgi vesicles has led to the identification of nucleotidases that convert glycosyltransferase-generated dinucleotides into the corresponding mononucleotides, thus playing a double function: their activity prevent inhibition of further glycosyl transfer by the accumulation of dinucleotides and the resulting mononucleotides are exchanged by specific membrane transporters for equimolecular amounts of sugar donors from the cytosol. Here, using a simple protocol for protein separation we isolated a bifunctional nucleotidase from $C$. albicans active on GDP and UDP that was characterized in terms of its molecular mass, response to bivalent ions and other factors, substrate specificity and affinity. Results are discussed in terms of the similarities and differences of this nucleotidase with similar counterparts from other organisms thus contributing to the knowledge of a bifunctional diphosphatase not described before in $C$. albicans.

\section{Introduction}

Candida species are the most frequent cause of nosocomial fungal infections in U.S. hospitals (Edmond et al. 1999; Wisplinghoff et al. 2004). C. albicans is by large the most frequently isolated member of the genus and lives as a commensal on healthy individuals in equilibrium with the host. However, under certain conditions, most commonly in immunocompromised individuals, this opportunistic pathogen becomes invasive causing disseminated candidiasis with a high rate of morbidity and mortality (Corner and Magee 1997; Garcia-Rubio et al. 2020; Kadosh and Mundodi 2020).

The fungal CW exhibits a characteristic composition consisting mainly of b-glucans, chitin and glycoproteins (Gow et al. 2017; Garcia-Rubio et al. 2020). These components do not exist in humans and therefore represent a potential target for antimicrobial drugs. On this basis, interest of this laboratory has dealt with the search of surface antigenic components such as glycoproteins and other components in human pathogenic fungi such as Candida and Sporothrix species. This has led us to the analysis of glycosyl transferases and glycosidases that participate in glycoprotein biosynthesis (Mora-Montes et al. 2009; López-Romero et al. 2011) and most recently on enzymes that participate in the final stages of glycoprotein assembly such as nucleoside diphosphatases (NDPases).

It is well documented that NDPases convert glycosyltransferase-generated nucleoside diphosphates into monophosphates thus preventing their accumulation and the ensuing inhibition of further sugar transfer 
as well as providing substrates that exit the Golgi lumen in exchange for equimolecular amounts of nucleotide sugars from the cytosol by specific antiporters (Abeijon et al. 1989; 1993; D'Alessio et al. 2003, 2005). The presence and function of NDPases has been reported in a number of both higher and lower eukaryotes (Brandan and Fleischer 1982; Yanagisawa et al. 1990; Wang and Guidotti, 1998; Trombetta and Helenius 1999; D’Alessio et al. 2003; Uccelletti et al. 2008; López-Esparza et al. 2013). Much of our knowledge about the roles of NDPases in vivo has been obtained through the isolation and phenotypic characterization of mutants encoding these enzymes. For instance, a null mutation in GDAl, the gene encoding for a Golgi GDPase in Saccharomyces cerevisiae, blocked O- and N-mannosylation of chitinase and carboxypeptidase $Y$ (Abeijon et al. 1993). In the same line, individual disruption of Spgda ${ }^{+}$and Spynd $1^{+}$genes coding for a GDPase/UDPase and an apyrase, respectively, did not affect cell viability of Schizosaccharomyces pombe, but the double mutant was lethal (D'Alessio et al. 2003). A null mutant of the Kluyveromyces lactis Klgda 1 gene, an ortholog of the S. cerevisiae gene ScGda1 coding for a Golgi UDPase, failed to transport GDP-mannose and UDP-GIcNAc into the Golgi lumen demonstrating the lack of GMP and UMP required as antiporters (López-Avalos et al. 2001). Moreover, the ORF of the GDA1 gene from the human pathogenic fungus Sporothrix schenckii fully restored the GDPase activity in a gda 1 null mutant of $S$. cerevisiae thereby proving the functionality of the ortholog (López-Esparza et al. 2013). A phenotypic analysis of a $C$. albicans mutant lacking a Golgi GDPase indicated that this NDPase is involved in cell wall composition, yeast-hypha transition and O-mannosylation (Herrero et al. 2002). To learn more about nucleotidases in this pathogen, here we report the purification to homogeneity and partial characterization of a membrane-bound enzyme whose properties are compatible with a bifunctional NDPase active on GDP and UDP.

\section{Materials And Methods}

Organism and growth conditions

The wild type strain ATCC 26555 of Candida albicans from the collection of the Department of Biology, University of Guanajuato, was used in this study. The organism was maintained on slants containing $0.3 \%$ yeast extract, $1.0 \%$ peptone, $2 \%$ dextrose, $\mathrm{pH} 7.8$ (YPD medium) solidified with $2 \%$ agar. For propagation, $C$. albicans was first grown at $28{ }^{\circ} \mathrm{C}$ in $15-\mathrm{ml}$ conical tubes containing $10 \mathrm{ml}$ of liquid YPD. After $24 \mathrm{~h}$, cells were counted and used to inoculate one-liter Erlenmeyer flasks containing $300 \mathrm{ml}$ of liquid YPD medium at a final density of $1 \times 10^{6}$ cells $/ \mathrm{ml}$. Flasks were incubated with rotary shaking (120 $\mathrm{rpm}$ ) at $28^{\circ} \mathrm{C}$ and, unless otherwise indicated, cells were collected after $18 \mathrm{~h}$ and processed as described below.

Cell breakage and preparation of the enzyme source

Cells were collected in a filtration unit using MF-Millipore, pore size $0.65 \mu \mathrm{m}$ (Merck), washed with $5 \mathrm{mM}$ imidazole buffer, $\mathrm{pH} 7.2$ and resuspended in the same buffer containing $2 \mu \mathrm{m}$ E-64 and $2 \mathrm{mM} \mathrm{PMSF}$ (buffer A) to minimize cysteine and serine protease activities, respectively, during breakage. The following next steps were carried out at $4{ }^{\circ} \mathrm{C}$. Yeast cells were disrupted mechanically with glass beads $(0.45-0.50$ 
$\mathrm{mm}$ in diameter) in a MSK cell homogenizer (Braun Melsungen, Germany) cooled by a stream of liquid $\mathrm{CO}_{2}$ by alternate 5-min periods of breakage and one-min of cooling until $15 \mathrm{~min}$ of breakage were completed. Cell disruption (over 90\%) was confirmed by phase contrast microscopy. It should be noticed that imidazole buffer was used only for cell disruption as Tris gave rise to a very foamy homogenate with reduced nucleotidase activity. The whole homogenate $(\mathrm{WH})$ was aspirated with a Pasteur pipette, placed in a $50-\mathrm{ml}$ conical tube and centrifuged at $10,000 \times \mathrm{g}$ for $15 \mathrm{~min}$. The sediment was discarded. The supernatant was recovered and centrifuged at $25,000 \times g$ for $15 \mathrm{~min}$. The pellet was discarded and the supernatant was collected and centrifuged at 100,000 $\times g$ for $1 \mathrm{~h}$. In some experiments, the supernatant was carefully decanted and kept at $4{ }^{\circ} \mathrm{C}$. The pellet, consisting of a mixed membrane fraction (MMF), was resuspended in buffer $\mathrm{A}$. NDPase activity was determined in the $\mathrm{WH}$, and the soluble (SN100K) and MMF fractions.

Solubilization of nucleotidase activity

The ability of three nonionic detergents to solubilize nucleotidase activity from MMF was tested. Briefly, aliquots $(2-4 \mathrm{ml})$ of the membrane fraction were gently shaken at $4{ }^{\circ} \mathrm{C}$ with either 0.5 or $1.0 \%(\mathrm{v} / \mathrm{v})$ of Lubrol WX, Igepal CA-630 or Triton X-100 (all from Merck). After 30 min, samples were centrifuged at $100,000 \times g$ for $1 \mathrm{~h}$. The supernatant, labeled as solubilized fraction (SF), was collected and the pellet was homogenized in a small volume $(1-2 \mathrm{ml})$ of $20 \mathrm{mM}$ Tris/HCl buffer, $\mathrm{pH}$ 7.2. Nucleotidase activity was assayed in both cell fractions as described below.

Nucleotidase assay

Nucleotidase activity was determined as described by Yanagisawa et al. (1990). Accordingly, reaction mixtures containing $20 \mathrm{mM}$ Tris-HCl buffer, pH 7.2, 0.1\% Tritón X-100, $2.5 \mathrm{mM} \mathrm{CaCl} 2,1 \mathrm{mM}$ GDP or UDP and the enzyme fraction (routinely $20 \mu \mathrm{l}$ ) in a total volume of $200 \mu \mathrm{l}$ were incubated at $37^{\circ} \mathrm{C}$. After 30 min, the reaction was stopped by adding $200 \mu \mathrm{l}$ of $2 \%$ SDS and the amount of released inorganic phosphate was measured spectrophotometrically by the method of Ames (1966) using a standard curve prepared with sodium phosphate. Unless otherwise indicated, specific activity was described as nmol $\mathrm{P} / \mathrm{min} / \mathrm{mg}$ protein. Protein was determined by the method of Bradford (1976) using bovine serum albumin to prepare a standard curve.

Purification of solubilized nucleotidase

Nucleotidase were purified to homogeneity by a simple, two-step procedure. Briefly, a 4-ml aliquot of the SF was layered on top of a column $(1 \times 10 \mathrm{~cm})$ of DE-52 equilibrated with $20 \mathrm{mM}$ Tris-HCl buffer, $\mathrm{pH} 7.2$, containing $0.05 \%$ Triton X-100 and $2.5 \mathrm{mM} \mathrm{CaCl}_{2}$ (buffer B). The column was washed with the same buffer followed by a 0-2 $\mathrm{M}$ discontinuous gradient of $\mathrm{NaCl}$ in buffer $\mathrm{B}$. Two-ml fractions were collected and used to measure activity and protein content. Most active fractions were mixed and the pool was subjected to size exclusion chromatography in a column $(1 \times 81 \mathrm{~cm})$ of Bio-Gel P-100 equilibrated with buffer $\mathrm{B}$. Fractions $(1.6 \mathrm{ml})$ were collected and used to measure activity and protein content. 
Proteins were separated by denaturing $12 \%$ polyacrylamide gel electrophoresis in a Mini-PROTEAN Tetra Vertical Electrophoresis Cell (Bio-Rad) according to the method of Laemmli (1970). Gels were stained with Coomassie Brilliant Blue R-250 and silver nitrate. In the first case, gels were shaken in a staining solution containing $10 \%$ ammonium sulfate, $0.1 \%$ Coomassie Brilliant Blue R-250, 3\% orthophosphoric acid and $20 \%$ ethanol for $12 \mathrm{~h}$ and destained for $2 \mathrm{~h}$ with deionized water (DW). In the second case, gels were washed thrice for 5 min with DW and fixed in a methanol:acetic acid solution (50\%:15\%, by vol) for 20 min. After two consecutive washings for 10 min with $50 \%$ methanol and DW, gels were immersed in $0.02 \%$ sodium thiosulfate for $90 \mathrm{sec}$. After washing twice for one min with DW, gels were incubated in darkness with $0.1 \%$ silver nitrate for $30 \mathrm{~min}$ at $4{ }^{\circ} \mathrm{C}$ and washed twice for one min. Protein bands were revealed by shaking the gels in a solution containing $2 \%$ sodium carbonate and $0.04 \%$ formaldehyde. Revealing was stopped by adding $5 \%$ acetic acid for $10 \mathrm{~min}$ and gels were placed in DW. With both staining methods, gels were analyzed in a $\mathrm{CHEMIDOC}^{\mathrm{TM}}{ }_{\mathrm{MP}}$ imaging system (Bio-Rad).

Bioinformatics

Bioinformatic analysis was carried out in several platforms including the NCBI (National Center for Biotechnology Information) database, the nonredundant protein sequence database (https://www.ncbi.nlm.nih,gov/) and the genetic sequence database of the NIH (National Institutes of Health, USA), where a collection of DNA sequences is available to the public. The analysis of sequence homology of genes coding for guanosine diphosphatase (GDPase) from C. albicans was carried out in the UniProtKB/Swiss-Prot (http://www.uniprot.org/) database.

Protein sequence analysis

Sequence of guanosine diphosphatase (GDA1) protein for strain SC5314 of C. albicans was obtained from the NCBI database in FASTA format, with access numbers CAD18870.1.

Statistics

Unless otherwise indicated, results presented are the average of three independent experiments run in triplicate. The analysis of variance was carried out using the Minitab tool, version 14 for Windows and data are reported as media values. ANOVA was used to compare data and detect significant differences based on statistical degrees of freedom and an error probability of $p \geq 0.05$.

\section{Results}

Bioinformatics

A search of GDPase in silico as described in Materials and methods revealed a GDA1p sequence of 599 aa with a putative molecular weight of $65.89 \mathrm{kDa}$ and a corresponding pl value of 5.64 (Fig. S1). 
Noteworthy, in silico search of UDPase protein in C. albicans met with failure indicating that genes/proteins associated with the enzyme have not yet been annotated in these organisms.

Growth and activity of NDPases

C. albicans was grown in YPD medium at $28{ }^{\circ} \mathrm{C}$ and specific activity on GDP and UDP was determined in the whole homogenate $(\mathrm{WH})$ at the indicated time points in Fig. 1a. Both GDPase and UDPase activities increased as a function of growth reaching a maximum after $18 \mathrm{~h}$ corresponding to the exponential phase of growth. Based on these results, further experiments were carried out in exponentially growing cells.

NDPase activity was measured in the cell fractions obtained after differential centrifugation of the WH as described in Materials and methods. As shown in Fig. 1b (inset), the highest and similar activity on both substrates was obtained in the mixed membrane fraction (MMF) isolated after centrifugation of the cell extract at 100,000 $\mathrm{x} g$ for $1 \mathrm{~h}$. As expected for soluble nucleotidases, a significant difference in activity on GDP and UDP was observed in the SN100K. Average activity in the MMF was 5.6fold higher with respect to the $\mathrm{WH}$.

Solubilization of NDPase activity from MMF

The ability of some non-ionic surfactants to solubilize NDPase activity was tested. Briefly, samples of the FMM (2-4 ml in $20 \mathrm{mM}$ Tris/HCl, pH 7.2) were mixed with either Lubrol WX, Igepal CA-630 and Triton X100 (all from Sigma) at 0.5 and $1 \%$ (by volume). Mixtures were gently shaken at $4{ }^{\circ} \mathrm{C}$ and after $30 \mathrm{~min}$, they were centrifuged at $100,000 \times \mathrm{g}$ for $1 \mathrm{~h}$ and the supernatant and pellet were saved. The latter was resuspended in the same initial volume of buffer. NDPase activity was then measured in SF's and the residual MMF as described in Materials and methods. As illustrated in Fig. 2, the best results were obtained with $0.5 \%$ Lubrol WX which gave rise to a SF with comparable specific activities of GDPase and UDPase (386.3). Increase of Lubrol WX to $1 \%$ reduced soluble activity by $16.5 \%$ and $36.5 \%$, respectively. On the other hand, treatment of the membrane fraction with Igepal CA-630 released SF's with specific activities below 75 that were slightly higher for GDPase. Likewise, incubation of MMF with $0.5 \%$ or $1 \%$ Triton X-100 yielded SF's with activities that ranged between 50 and 100. In all cases, activity in the residual MMF remained at about 60 and below. Based on these results, solubilization of NDPase activity with $0.5 \%$ Lubrol WX was chosen for further experiments.

\section{Purification of solubilized NDPases}

For isolation of the enzyme protein, the solubilized fraction enriched with NDPase activity was subjected to a simple, two-step protocol involving ion exchange and size exclusion chromatographies. Accordingly, SF (routinely $4 \mathrm{ml}$ ) was loaded on a column $(1 \times 10 \mathrm{~cm})$ of DE-52 equilibrated with $20 \mathrm{mM} \mathrm{Tris} / \mathrm{HCl}$ buffer, $\mathrm{pH} 7.2$ containing $0.05 \%$ Lubrol WX (buffer B). The column was washed with the same buffer until the first protein-containing fraction emerged and the wash eluate was discarded. Then, ten 2-ml fractions were collected before applying a discontinuous gradient of 0 to $2 \mathrm{M} \mathrm{NaCl}$ in buffer $\mathrm{B}$. As shown in Fig. 3a, 
three peaks containing UDPase were eluted. Peak $A$ appeared at the start of the salt gradient whereas peak B eluted at $0.5 \mathrm{M} \mathrm{NaCl}$. Both $A$ and B peaks co-eluted with smaller peaks of GDPase. An extended, low peak (C) of GDPase-free UDPase activity appeared between fractions 17-21 that was not considered for further analysis. Most active fractions of peaks $A$ and $B$ were pooled and concentrated to $1.0-1.5 \mathrm{ml}$ in a 10-ml Amicon stirred cell (Merck). Further enzyme separation was carried out by size exclusion chromatography. To this purpose, the pool was placed onto a column $(1 \times 81 \mathrm{~cm})$ of Bio-Gel P-100 equilibrated with buffer $B$ and fractions $(1.6 \mathrm{ml})$ were collected on the basis of the Ve/Vo elution quotient. To avoid contamination with spurious proteins, only the most active, single fraction was collected and used for further analysis. Representative results from several experiments are illustrated in Fig. 3b. UDPase and GDPase co-eluted with a molecular mass of $65 \mathrm{kDa}$ as determined in the same column calibrated with proteins of known MW (not shown).

\section{Electrophoresis}

Purity of the enzyme protein was assessed by denaturing SDS-PAGE in $12 \%$ gels that were stained with either Coomassie Brilliant Blue or silver nitrate as described in Materials and methods. Results are illustrated in Fig. 4. Stain of the gel with either Coomassie Blue or silver nitrate revealed a single protein of $60.5 \mathrm{kDa}$. The more sensitive stain revealed two other proteins of 118.4 and $250 \mathrm{kDa}$. The bifunctional enzyme was by large the most abundant and densitometry indicated a purity of about $90 \%$ (Fig. 5).

\section{Characterization of purified NDPase}

Effect of ions on enzyme activity and substrate specificity

In most organisms, divalent cations commonly $\mathrm{Ca}^{2+}, \mathrm{Mg}^{2+}$ and $\mathrm{Mn}^{2+}$ affect NDPase activity. For instance, a highly GDP-specific Golgi GDPase from S. cerevisiae, required $\mathrm{Ca}^{2+}$ for maximal activity and other cations such as $\mathrm{Mn}^{2+}$ and $\mathrm{Mg}^{2+}$ also activated the enzyme (Yanagisawa et al. 1990). In mammalian cells, a soluble and a membrane-bound GDPase/UDPase have been localized to the ER. The soluble enzyme is active with $\mathrm{Ca}^{2+}, \mathrm{Mg}^{2+}$ or $\mathrm{Mn}^{2+}$ whereas the insoluble enzyme fully depends on $\mathrm{Ca}^{2+}$ for activity (Wang and Guidotti, 1998; Trombetta and Helenius, 1999; Failer et al. 2002). Here, activity of the enzyme on GDP increased over $40 \%$ in the presence of $5-10 \mathrm{mM} \mathrm{Ca}^{2+}$ whereas $\mathrm{Mg}^{2+}$ was less efficient and both were inhibitory at concentrations above $10 \mathrm{mM}$. $\mathrm{Mn}^{2+}$ inhibited hydrolysis of GDP at all tested concentrations (Fig. 6a). Activity on UDP was less responsive to $\mathrm{Ca}^{2+}$ which stimulated $17 \%$ at $5 \mathrm{mM}$ and became inhibitory at $10 \mathrm{mM} . \mathrm{Mg}^{2+}$ and $\mathrm{Mn}^{2+}$ were inhibitory at all tested concentrations (Fig. 6b). These results led us to determine whether the substrate specificity was influenced by calcium ions. Results shown in Table 1 indicate that in the presence of $\mathrm{Ca}^{2+}$ the enzyme showed a relative activity of $100 \%$ on GDP and UDP and exhibited 40 and $48 \%$ activity on the corresponding monophosphates. The latter activity was not observed in the absence of $\mathrm{Ca}^{2+}$ while that on GDP and UDP was slightly reduced. In any case, no activity was observed on adenine or cytosine nucleotides.

Substrate affinity and effect of some phospholipids on enzyme activity 
Enzyme activity was measured as a function of increasing concentrations of GDP and UDP. With any nucleotide, enzyme activity followed hyperbolic kinetics (Figs. 7a, b) that was used to estimate the $K_{m}$ and $V_{\max }$ values by the double-reciprocal method of Lineweaver and Burk (Fig. 7c, d). The enzyme exhibited a slightly higher affinity for GDP over UDP as judged for the $\mathrm{K}_{\mathrm{m}}$ values of 0.46 and $0.62 \mathrm{nmol}$, respectively. Corresponding $\mathrm{V}_{\max }$ values were 33.5 and $25.2 \mathrm{nmol} \mathrm{P} / \mathrm{min} / \mathrm{mg}$. To determine whether the enzyme required glycerophospholipids for activity, this was assayed in the absence and presence of common phospholipids, either individually or in combination. Though enzyme did not depend on exogenously added phospholipids, these stimulated both activities in comparable ranges, varying from 24.6 (PE) to 25.4 (PI + PE and PI + PE + PG) for GDPase and from 21.4 (PG) to 24.4 (PE) for UDPase (Fig. 8a-h and Table S1).

\section{Discussion}

Growth of $C$. albicans was concomitant with a parallel increase of GDPase and UDPase activities which reached maximum levels after $18 \mathrm{~h}$, corresponding to the logarithmic phase of growth. Further processing of $18 \mathrm{~h}$-old cells by differential centrifugation led to the isolation of a high-speed, mixed membrane fraction (MMF) enriched with very similar activities of both diphosphatases. Average enzyme enrichment was about 5.6-fold with respect to the whole homogenate. A significant difference in the activity of the enzymes was observed only in the high-speed soluble fraction. This activity may correspond to the ubiquitous, soluble nucleotidase of $45 \mathrm{kDa}$, active on GDP, UDP and IDP that prevents accumulation of UDP following reglucosylation reactions involved in glycoprotein folding and quality control in the ER lumen (Trombetta and Helenius 1999).

Non-ionic detergents commonly used to solubilize membrane-bound enzymes include Triton X-100, Igepal CA-630 and Lubrol WX. For instance, a Golgi GDPase from S. cerevisiae was purified and characterized after solubilization with Triton X-100 (Yanagisawa et al. 1990). Here, we used these surfactants at 0.5 and $1 \%$ to extract diphosphatase activity from the MMF. Best results were obtained with Lubrol WX at $0.5 \%$ as it yielded a soluble extract enriched with the same levels of GDPase and UDPase. Solubilization with $1 \%$ rendered a less active SF and a slightly diminished UDPase activity with respect to GDPase. These results, altogether with those of cellular distribution, particularly in the MMF, suggested that both diphosphatase activities were associated to a single, bifunctional protein.

Enzyme purification was carried out by a simple procedure involving ion exchange and size exclusion chromatographies. In the first step, enzyme activity consistently separated into two co-eluting peaks: one at the very start of the salt gradient and another at the start of $0.5 \mathrm{M} \mathrm{NaCl}$, suggesting the presence of slightly ionic species. In both peaks, GDPase activity was lower than that of UDPase, a difference probably due to a inhibitory effect of the salt on the hydrolysis of GDP. The extended peak $C$ showing UDPase activity only, was not considered for further analysis. In any case, most active fractions in peaks A and B were pooled and further separated by size exclusion in Bio-Gel P-100. In this case, both diphosphatase activities co-eluted in a sharp, single peak thus reinforcing the idea of a GDPase/UDPase bifunctional polypeptide whose molecular mass was calculated as $65 \mathrm{kDa}$ by column chromatography. 
Here, the difference in activity on GDP and UDP was not as marked as in DE-52 probably because of salt elimination. In several experiments, only the most active peak fraction was collected to avoid contamination with spurious proteins flanking the activity peak. This strategy precluded the estimation of enzyme recovery and purification. Purity of the bifunctional protein to homogeneity was assessed by denaturing, analytical electrophoresis in gels stained with either Coomassie Blue or silver nitrate. By this method, molecular mass was calculated as $60.5 \mathrm{kDa}$ and densitometry after staining with silver revealed a purity of $90 \%$. The nature of bands of 118.4 and $250 \mathrm{kDa}$ remains unknown.

The molecular weight (MW) of several reported diphosphatases is variable. Accordingly, GDPase/UDPase's from S. cerevisiae (Abeijon et al. 1989) and Drosophila melanogaster (Knowles 2011) exhibited MW's of $56 \mathrm{kDa}$ whereas a GDPase/ATPase from Tetrahymena thermophila had a molecular mass of $66 \mathrm{kDa}$ (Smith et al. 1997). In Schizosaccharomyces pombe, two nucleoside diphosphatases were described: a GDPase/UDPase (Spgda1p) and an apyrase (Spyndp1p) of 61.6 and $64.6 \mathrm{kDa}$, respectively (Alessio et al. 2003). The molecular mass calculated here for the $C$. albicans GDPase/UDPase is well within the range reported in other organisms.

It is well documented that bivalent ions, commonly $\mathrm{Ca}^{2+}, \mathrm{Mg}^{2+}$ and $\mathrm{Mn}^{2+}$, are either strictly required or stimulate nucleoside diphosphatase activity. Thus, it has been described that a Golgi GDPase purified from $S$. cerevisiae requires $\mathrm{Ca}^{2+}$ for maximum activity whereas $\mathrm{Mn}^{2+}$ and $\mathrm{Mg}^{2+}$ activate the enzyme (Yanagisawa et al. 1990). In the same line, both a GDPase/UDPase and an apyrase from S. pombe required $\mathrm{Ca}^{2+}, \mathrm{Mg}^{2+}$ or $\mathrm{Mn}^{2+}$ for activity (D'Alessio et al. 2003). Likewise, a human Golgi UDPase was stimulated by $\mathrm{Ca}^{2+}$ whereas $\mathrm{Mg}^{2+}$ and $\mathrm{Mn}^{2+}$ had a lower or minimal effect (Wang and Guidotti 1998). A mammalian UDPase associated with the ER and also with pre-Golgi intermediates was strongly activated by $\mathrm{Ca}^{2+}$ but was insensitive to $\mathrm{Mg}^{2+}$ (Failer et al. 2002). In a report closely related with this study, it was observed that activity of GDPase in C. albicans increased $100 \%$ in the presence of $\mathrm{Mg}^{2+}$ (Herrero et al. 2002), in contrast with $S$. cerevisiae where $\mathrm{Ca}^{2+}$ is the preferred cation for GDP hydrolysis (Yanagisawa et al. 1990). Taken together, these contrasting findings reveal that the response of these enzymes to bivalent ions is quite diverse. Here, though these cations were not required for activity of GDPase/UDPase, in several experiments we observed that hydrolysis of GDP was stimulated over $40 \%$ by $\mathrm{Ca}^{2+}$ whereas $\mathrm{Mg}^{2+}$ was less efficient and $\mathrm{Mn}^{2+}$ was inhibitory. On the other hand, hydrolysis of UDP was less responsive to $\mathrm{Ca}^{2+}$ and $\mathrm{Mg}^{2+}$ and $\mathrm{Mn}^{2+}$ were inhibitory. At this point, it is worth pointing out whether a bifunctional nucleotidase has a catalytic domain to interact with both GDP and UDP or it exhibits two specific sites, one for each nucleotide. In terms of the structural difference between these diphosphates at the nucleobase level, the second alternative seems more plausible. This would imply a differential response of the hydrolysis of GDP and UDP to external influencers of enzyme activity including bivalent ions and other factors.

It has been described that some NDPases are able to hydrolyze nucleoside mono-, di- and triphosphates and that some cations, commonly $\mathrm{Ca}^{2+}{ }^{2}$, may change the substrate specificity (Wang and Guidotti, 1998; Yanagisawa et al. 1990; Failer et al. 2002; D’Alessio et al. 2003). Here, maximum activity on both GDP 
and UDP was observed in the presence of $\mathrm{Ca}^{2+}$ and a lower but significant breakdown of GMP and UMP was also detected. Hydrolysis of mononucleotides, which did not occur in the absence of the cation, is in contrast with a Golgi GDPase from S. cerevisiae that failed to breakdown nucleoside monophosphates in the presence of $10 \mathrm{mM} \mathrm{Ca}^{2+}$ (Yanagisawa et al. 1990) and also with the inactivity of a rat liver ER UDPase (Trombetta and Helenius 1999) and a human Golgi UDPase (Wang and Guidotti 1998) on GMP and UMP. In a previous study, we isolated a similar GDPase/UDPase bifunctional enzyme from the mycelial morphotype of Sporothrix schenckii that was equally active on GMP and UMP (30 and 35\% relative to GDP and UDP, respectively) in the presence but not in the absence of $\mathrm{Ca}^{2+}$ (to be published). Here, except for a trace activity on UTP, triphosphates were not substrates for the enzyme indicating the absence of apyrase activity.

Substrate affinity values reported in the literature for NDP'ases are variable. For instance, UDP was a better substrate than GDP or other NDP's for a human UDPase (Wang and Guidotti, 1998) whereas a GDP/UDPase from S. pombe was slightly more active on UDP than on GDP (D'Alessio et al. 2003). In the same line, a bovine liver ER-UDPase acting on UDP and GDP showed an apparent $\mathrm{Km}$ of 0.2-0.5 mM for both NDP's when assayed in the presence of saturating concentrations of $\mathrm{Ca}^{2+} \mathrm{or} \mathrm{Mg}^{2+}$ (Trombetta and Helenius 1999) whereas an insect $\mathrm{Ca}^{2+}$-dependent enzyme and insensitive to $\mathrm{Mg}^{2+}$ had a $\mathrm{Km}$ for UDP of $216 \mu \mathrm{M}$ (Failer et al. 2002). A highly specific Golgi-GDPase purified from S. cerevisiae exhibited an apparent Km for GDP of $0.1 \mathrm{mM}$ and a Vmax of $4.9 \mathrm{mmol} / \mathrm{min} / \mathrm{mg}$ (Yanagisawa et al. 1990). Here, assay of enzyme activity as a function of substrate concentration showed hyperbolic kinetics for both GDP and UDP and $\mathrm{Km}$ values revealed a higher affinity for GDP, namely, 0.46 vs 0.62 . Corresponding values of Vmax were 33.5 and $25.2 \mathrm{nmol} \mathrm{Pi} / \mathrm{min} / \mathrm{mg}$. These values are significantly lower than other reported findings indicating a higher affinity of the enzyme purified in this study for both NDP's.

Finally, the membrane-bound enzyme isolated in this study did not depend on glycerophospholipids for activity, though these increased hydrolysis of GDP and UDP to $21-25 \%$ either alone or in combination. This may indicate either that the enzyme is embedded in the membrane with the catalytic site oriented to the lumen of the organelle as it is the case for other NDPases or that its activity does not depend on hydrophobic effectors.

\section{Declarations}

Funding Part of this study was supported by project "Analisis comparativo de nucleosido difosfatasas (UDPasa y GDPasa) en Candida albicans y C. parapsilosis. Convocatoria Institucional de Investigación Científica-2018, DAIP, Universidad de Guanajuato, México.

Acknowledgements Thanks are given to Dirección de Apoyo a la Investigación y al Posgrado, Universidad de Guanajuato for financial support. II) - Apoyo a Niveles II, III y Eméritos en el Sistema Nacional de Investigadores (S.N.I). Authors wish to thank LCAFyS. Francisco J. Alcantar-Aranda for its help in bioinformatic analysis. 
Author's contribution All authors contributed to the study conception and design. Material preparation, data collection and analysis were performed by Jaime A. Bibián-García, Lilia M. Almanza-Villegas, Jorge A. Ortiz-Ramírez and C. Cano-Canchola. M. Cuéllar-Cruz and Everardo López-Romero wrote the paper. All authors read and approved the final manuscript.

Availability of data and materials All data generated or analyzed during this study are included in this published article.

Conflict of interest The authors declare that they have no conflict of interest.

Ethical approval The authors confirm that not ethical approval was required as the research in this article involved micro-organisms only.

Consent for publication All authors read and consent to publish this manuscript.

\section{References}

Abeijon C, Orlean P, Robbins PW et al (1989) Topography of glycosylation in yeast: characterization of GDPmannose transport and lumenal guanosine diphosphatase activities in Golgi-like vesicles. Proc Nat Acad Sci USA 86: 6935-6939. https://doi.org/10.1073/pnas.86.18.6935

Abeijon C, Yanagisawa K, Mandon EC et al (1993) Guanosine diphosphatase is required for protein and sphingolipid glycosylation in the Golgi lumen of Saccharomyces cerevisiae. J Cell Biol 122: 307323. https://doi.org/10.1083/jcb.122.2.307

Ames BN (1966) Assay of inorganic phosphate, total phosphate and phosphatases. Meth Enzymol 8:115118. https://doi.org/10.1016/0076-6879(66)08014-5

Bradford MM (1976) A rapid and sensitive method for the quantitation of microgram quantities of protein utilizing the principle of protein-dye binding. Anal Biochem 72: 248-254. https://doi.org/10.1016/00032697(76)90527-3

Brandan E, Fleischer B (1982) Orientation and role of nucleosidediphosphatase and 5'-nucleotidase in Golgi vesicles from rat liver. Biochemistry 21: 4640-4645. https://doi.org/10.1021/bi00262a019

Corner BE, Magee PT (1997) Candida pathogenesis: unraveling the threads of infection. Curr Biol 7: R691-R694. https://doi.org/10.1016/S0960-9822(06)00357-5

D’Alessio C, Trombetta ES, Parodi AJ (2003) Nucleoside diphosphatase and glycosyltransferase activities can localize to different subcellular compartments in Schizosaccharomyces pombe. J Biol Chem 278: 22379-22387. https://doi.org/10.1074/jbc.M300892200

D'Alessio C, Caramelo JJ, Parodi AJ (2005) Absence of nucleoside diphosphatase activities in the yeast secretory pathway does not abolish nucleotide sugar-dependent protein glycosylation. J Biol Chem 280: 
Edmond MB, Wallace SE, McClish DK (1999) Nosocomial bloodstream infections in United States hospitals: a three-year analysis. Clin Infect Dis 29: 239-244. https://doi.org/10.1086/520192

Failer BU, Braun N, Zimmermann H (2002) Cloning, expression, and functional characterization of a $\mathrm{Ca}^{2+}$ dependent endoplasmic reticulum nucleoside diphosphatase. J Biol Chem 277: 36978-36986. https://doi.org/10.1074/jbc.M201656200

Garcia-Rubio R, de Oliveira HC, Rivera J et al (2020) The fungal cell wall: Candida, Cryptococcus, and Aspergillus species. Front Microbiol 10: 2993. doi:10.3389/fmicb.2019.02993

Gow, N. A., Latge, J. P., \& Munro, C. A. (2017). The fungal cell wall: structure, biosynthesis, and function. Microbiology spectrum, 5(3), 5-3. https://doi.org/10.1128/microbiolspec.FUNK-0035-2016

Herrero AB, Uccelletti D, Hirschberg CB et al (2002) The Golgi GDPase of the fungal pathogen Candida albicans affects morphogenesis, glycosylation, and cell wall properties. Euk Cell. DOI:

10.1128/EC.1.3.420-431.2002

Kadosh D, Mundodi V (2020) A re-evaluation of the relationship between morphology and pathogenicity in Candida species. J Fungi 6:1-8. https://doi.org/10.3390/jof6010013

Knowles A (2011) The GDA_CD39 superfamily: NTPDases with diverse functions. Purinergic signaling 7: 21-45. https://doi.org/10.1007/s11302-010-9214-7

Laemmli UK (1970) Cleavage of the structural proteins during the assembly of the head of bacteriophage T4. Nature 227: 680-685. https://doi.org/10.1038/227680a0

López-Ávalos MD, Uccelletti D, Abeijon, C et al (2001) The UDPase activity of the Kluyveromyces lactis Golgi GDPase has a role in uridine nucleotide sugar transport into Golgi vesicles. Glycobiology 11:413422. https://doi.org/10.1093/glycob/11.5.413

López-Esparza A, Álvarez-Vargas, A, Mora-Montes HM et al (2013) Isolation of Sporothrix schenckii GDA1 and functional characterization of the encoded guanosine diphosphatase activity. Arch Microbiol 195: 499-506. https://doi.org/10.1007/s00203-013-0901-y

Lopez-Romero E, Reyes-Montes MR, Pérez-Torres A et al (2011) Sporotrichosis schenckii complex and sporotrichosis, an emerging health problem. Future Microbiol 6: 85-102.

https://doi.org/10.2217/fmb.10.157

Mora-Montes HM, Ponce-Noyola P, Villagómez-Castro JC et al (2009). Protein glycosylation in Candida. Future Microbiol 4: 1167-1183. https://doi.org/10.2217/fmb.09.88 
Smith TM, Kirley TL, Hennessey TM (1997) A soluble ecto-ATPase from Tetrahymena thermophila: purification and similarity to the membrane-bound ecto-ATPase of smooth muscle. Arch Biochem Biophys 337: 351-359. https://doi.org/10.1006/abbi.1996.9779

Trombetta ES, Helenius A (1999) Glycoprotein reglucosylation and nucleotide sugar utilization in the secretory pathway: identification of a nucleoside diphosphatase in the endoplasmic reticulum. EMBO J 18: 3282-3292. https://doi.org/10.1093/emboj/18.12.3282

Uccelletti D, Pascoli A, Farina F et al (2008) APY-1, a novel Caenorhabditis elegans apyrase involved in unfolded protein response signalling and stress responses. Mol Biol Cell 19: 1337-1345. https://doi.org/10.1091/mbc.e07-06-0547

Wang TF, Guidotti G (1998) Golgi localization and functional expression of human uridine diphosphatase. J Biol Chem 273: 11392-11399. https://doi.org/10.1074/jbc.273.18.11392

Wisplinghoff H, Bischoff T, Tallent SM (2004) Nosocomial bloodstream infections in United States hospitals: analysis of 24,179 cases from a perspective nationwide surveillance study. Clin Infect Dis 39 : 309-317. https://doi.org/10.1086/421946

Yanagisawa K, Resnick D, Abeijon C et al. (1990) A guanosine diphosphatase enriched in Golgi vesicles of Saccharomyces cerevisiae. 265: 19351-19355. https://doi.org/10.1016/S0021-9258(17)30665-8

\section{Tables}

Due to technical limitations, table 1 is only available as a download in the Supplemental Files section.

\section{Figures}


Fig. 1 Bibián-García et al. 2021

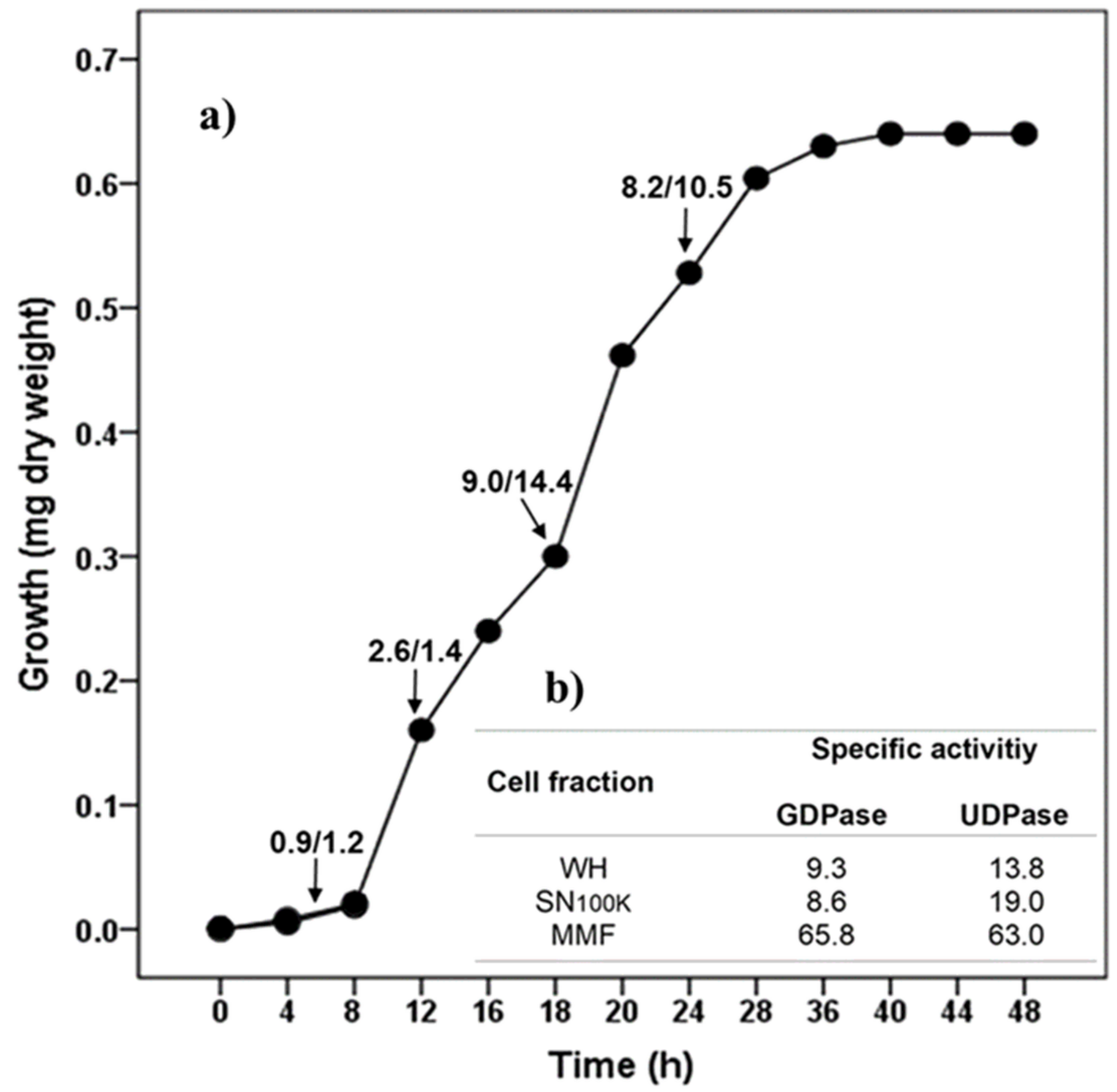

Figure 1

Growth of C. albicans ATCC 26555 in YPD medium and nucleotidase activity. One-liter Erlenmeyer flasks containing $300 \mathrm{ml}$ of YPD medium were inoculated with C. albicans at a final density of $106 \mathrm{cell} / \mathrm{s} / \mathrm{ml}$ and shaken $(120 \mathrm{rpm})$ at $28 \mathrm{oC}$. Growth was measured at the indicated times. At the indicated time points, cultures were processed as described in Materials and methods to determine specific activity of GDPase/UDPase in the whole cell homogenate (a). In addition, the whole cell extract was subjected to 
differential centrifugation and the obtained cell fractions were used to measure protein and hydrolysis of GDP and UDP (b).

\section{Fig. 2 Bibián-García et al. 2021}

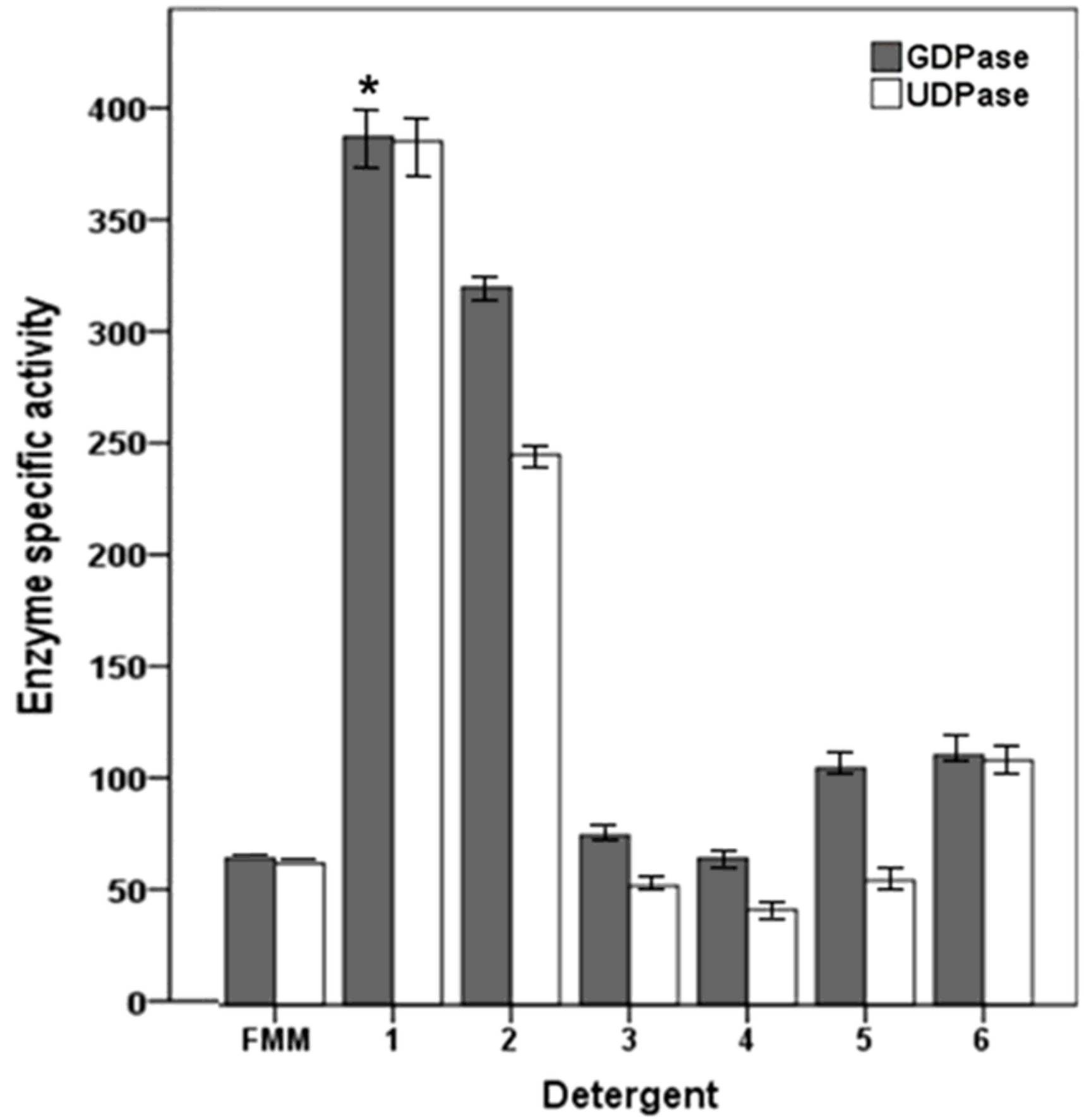

Figure 2

Solubilization of nucleotidase activity. The MMF (2-4 ml) obtained as described in Fig. 1b was mixed with the non-ionic detergents Lubrol WX $(1,2)$, Igepal CA-630 $(3,4)$ or Triton X-100 $(5,6)$ at concentrations of $0.5 \%(1,3,5)$ and $1 \%(2,4,6)$ (by vol) and gently shaken at $4 \mathrm{oC}$. A control MMF sample was mixed with 
buffer. After 30 min, mixtures were centrifuged at $100,000 \times \mathrm{g}$ for $1 \mathrm{~h}$. The supernatants, labeled as SF's, were collected and used to measure protein and GDPase and UDPase as described in the text.

\section{Fig. 3 Bibián-García et al. 2021}

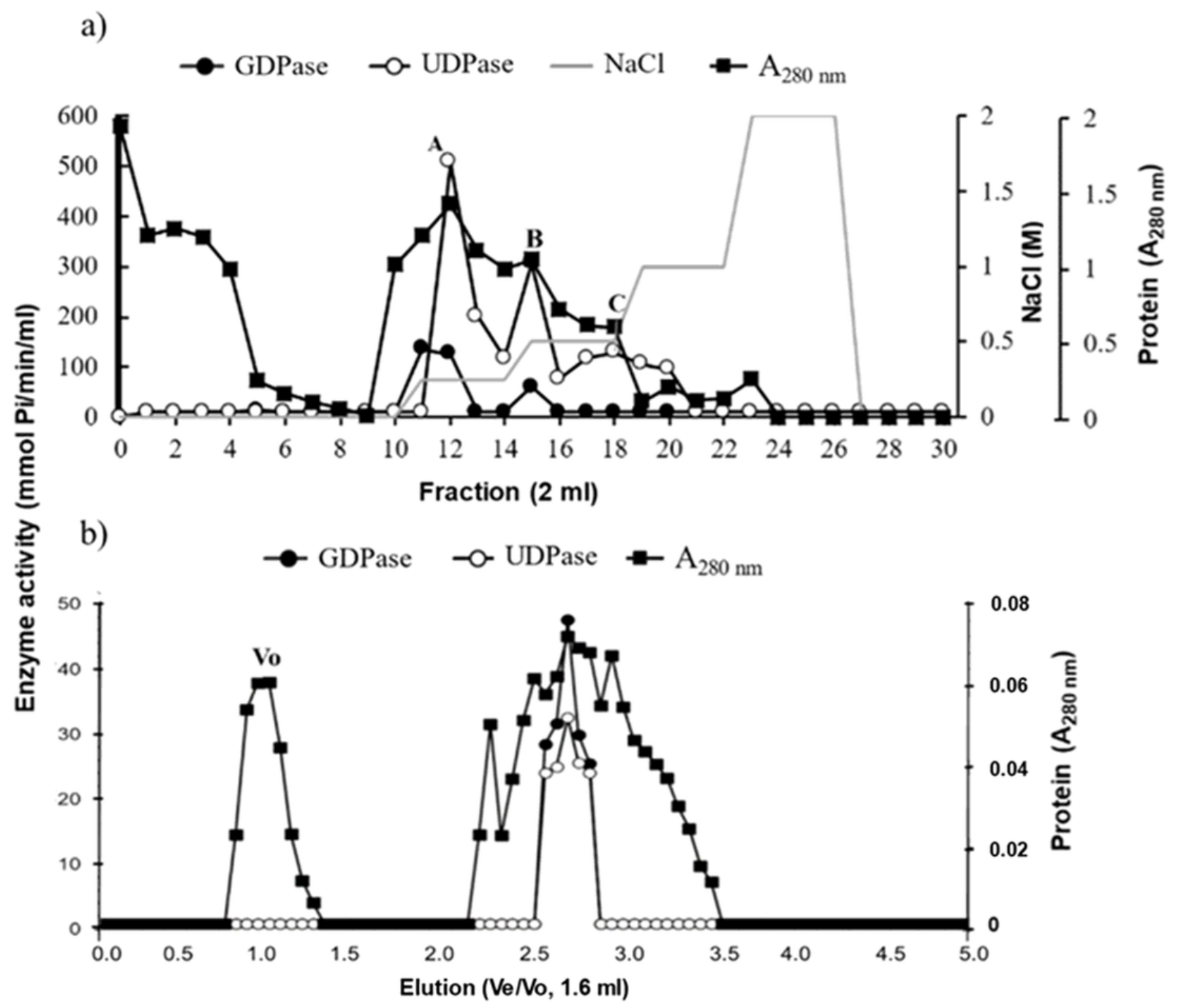

Figure 3

Purification of nucleotidase. A sample (routinely $4 \mathrm{ml}$ ) of the SF obtained after extraction of MMF with $0.5 \%$ Lubrol WX was layered on top of a column $(1 \times 10 \mathrm{~cm})$ of DE-52 equilibrated with buffer $B$ and the sample was eluted with the same buffer followed by a discontinuous $0-2 \mathrm{M} \mathrm{NaCl}$ gradient. Fractions (2 $\mathrm{ml}$ ) were collected and used to measure protein and hydrolysis of GDP and UDP (a). Most active fractions of peaks $A$ and $B$ were pooled and the pool was subjected to size exclusion chromatography in a column $(1 \times 81 \mathrm{~cm})$ of Bio-Gel P-100 equilibrated with buffer B. The sample was eluted with the same buffer and fractions $(1.6 \mathrm{ml})$ were collected according to their Ve/Vo. Fractions were used to measure protein and 
hydrolysis of GDP and UDP as described in the text (b). Only the most active fraction enriched with both nucleotidases was collected and saved for further analysis.

\section{Fig. 4 Bibián-García et al. 2021}

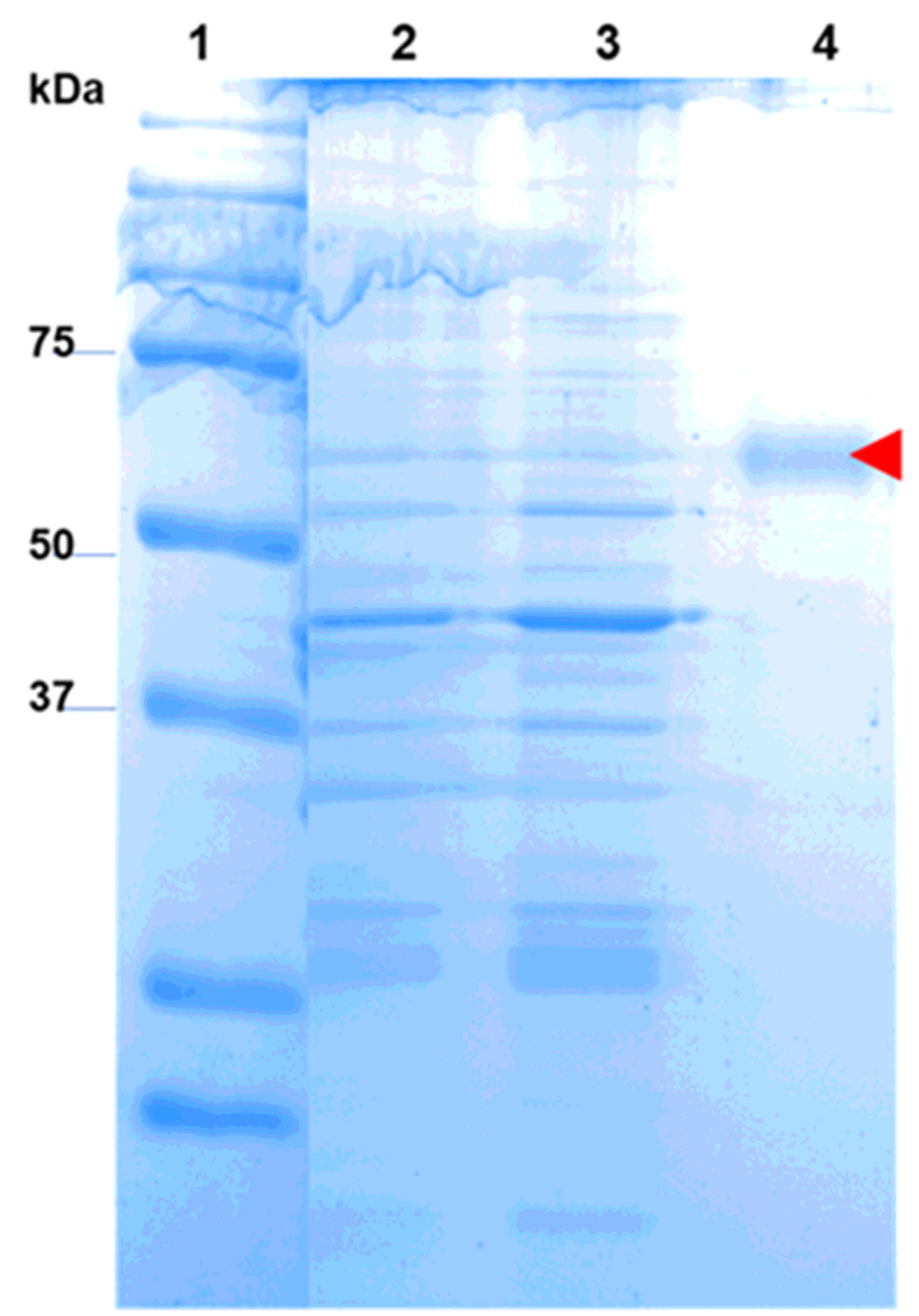

\section{Figure 4}

Analytical electrophoresis of nucleotidase. An aliquot of the enzyme separated in Bio-Gel P-100 was subjected to denaturing electrophoresis in $12 \%$ polyacrylamide gels of $1.5 \mathrm{~mm}$ according to Laemmli 
(1970). Gel was processed and stained with Coomassie Brilliant Blue as described in Materials and methods. Bands were analyzed and images were captured in a CHEMIDOCTMMP imaging system.

Fig. 5 Bibián-García et al. 2021
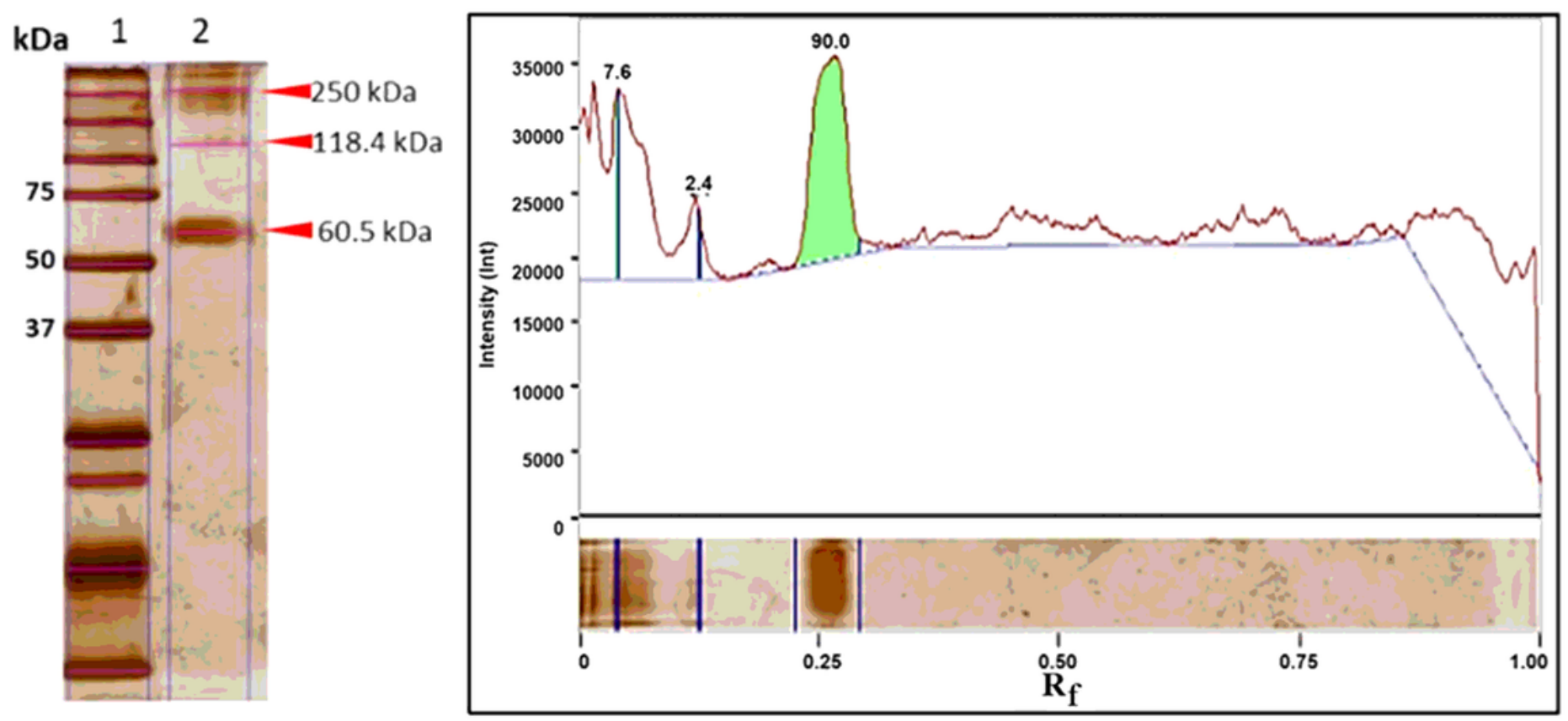

Figure 5

Same as legend of Fig. 4 except that the gel was stained with silver nitrate.

Fig. 6 Bibián-García et al. 2021
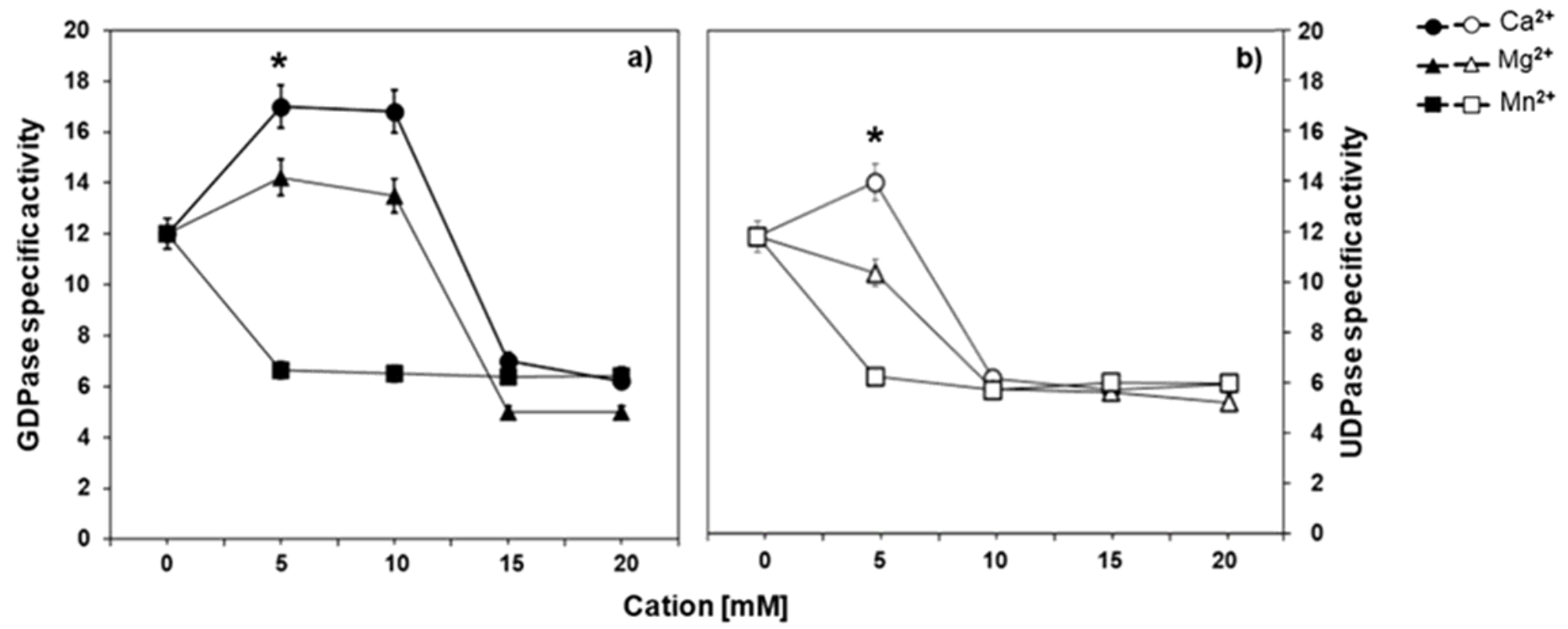

Figure 6 
Effect of bivalent ions on the bifunctional nucleotidase enzyme. Hydrolysis of GDP (a) and UDP (b) by the purified nucleotidase was measured in the presence of the indicated concentrations of $\mathrm{Ca} 2+, \mathrm{Mg} 2+$ or $\mathrm{Mn} 2+$ as described in the text. All other ingredients of the reaction mixture remained unchanged. Results shown are the average of three independent experiments run in duplicate.

Fig. 7 Bibián-García et al. 2021
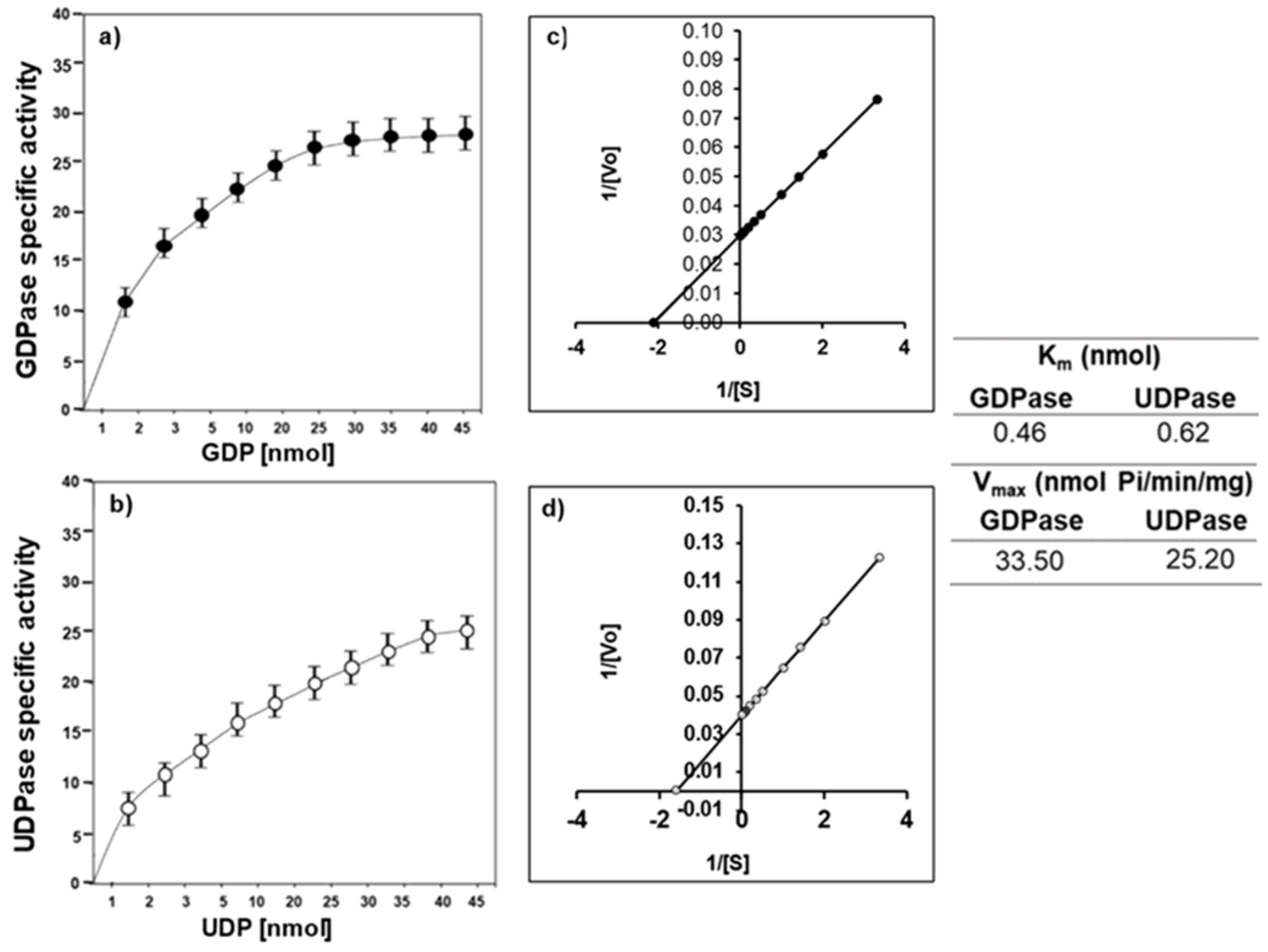

\section{Figure 7}

Measurement of nucleotidase activity as a function of increasing concentrations of substrate. Hydrolysis of GDP (a) and UDP (b) was measured at the indicated concentrations of diphosphates. All other ingredients of the reaction mixture remained unchanged. Activity data shown in (a) were used to determine $\mathrm{Km}$ and Vmax by the reciprocal plots of Lineweaver and Burk, as indicated in (c) and (d) for GDP and UDP, respectively. Values of enzyme constants are compiled in the table at right. 
Fig. 8 Bibián-García et al. 2021

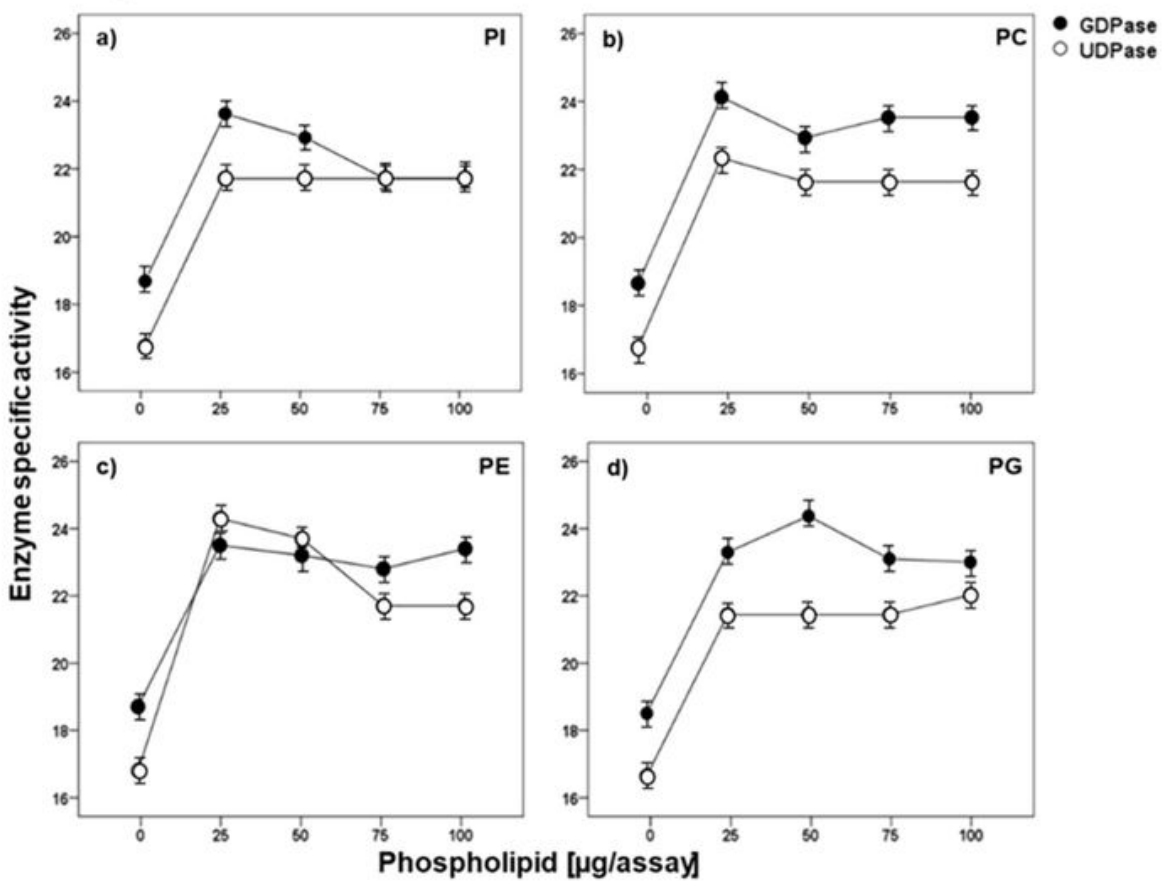

Fig. 8 Bibián-García et al. 2021 Continued...

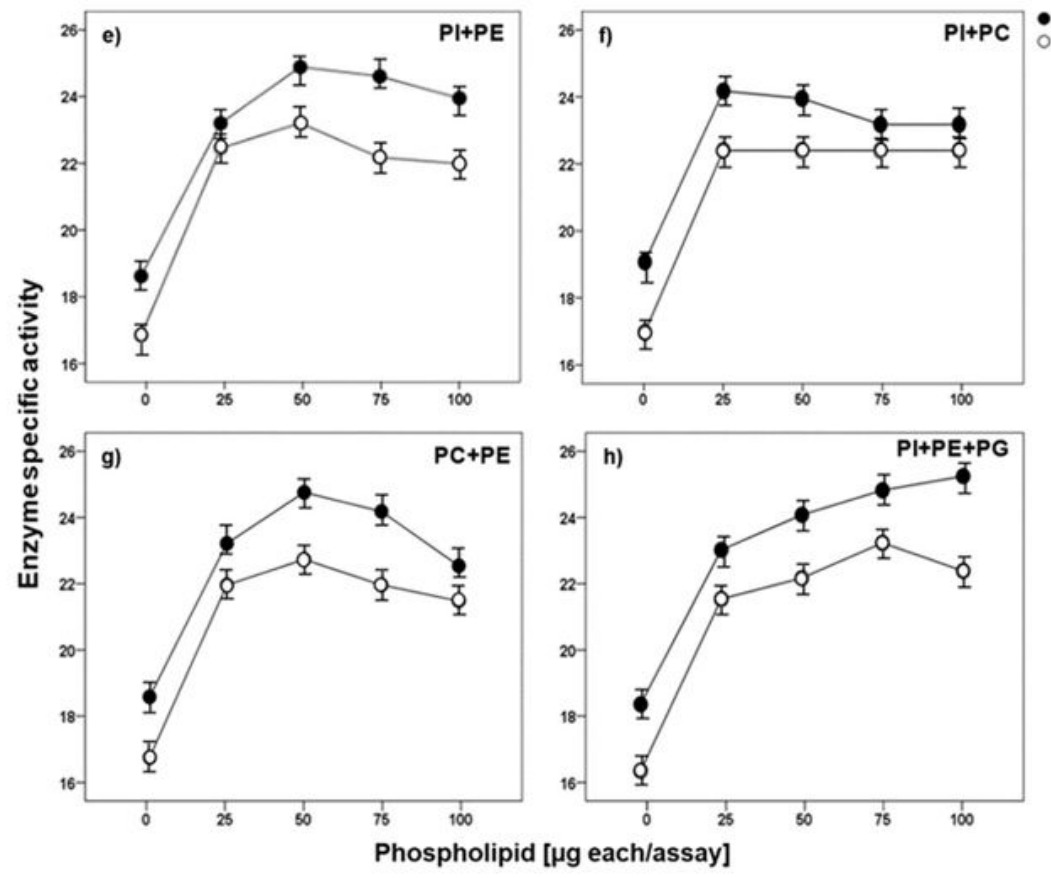

\section{Figure 8}

Influence of some common glycerophospholipids on hydrolysis of GDP and UDP by the purified nucleotidase. Hydrolysis of GDP (closed symbols) and UDP (open symbols) was measured in the presence of increasing concentrations of the indicated individual (a-d) and combined (e-h) phospholipids as described in the text. All other ingredients of the reaction mixture remained unchanged. Results shown are the average of two independent experiments run in duplicate. 


\section{Supplementary Files}

This is a list of supplementary files associated with this preprint. Click to download.

- Table.1.tif

- STable.1.tif

- SFig.1.tif 